\title{
A review of the genus Toxorhina Loew from China, with descriptions of three new species (Diptera, Limoniidae, Limoniinae)
}

\author{
Xiao Zhang', Yan $\mathrm{Li}^{2}$, Ding Yang' \\ I Department of Entomology, China Agricultural University, Beijing 100193, China 2 Plant Protection College, \\ Shenyang Agricultural University, Shenyang 110866, China \\ Corresponding author: Ding Yang (dyangcau@126.com; dyangcau@aliyun.com)
}

Academic editor: V. Blagoderov | Received 15 March 2014 | Accepted 19 January 2015 | Published 2 February 2015

http://zoobank.org/FA76FB4E-4595-4649-987D-BABBA1FBF993

Citation: Zhang X, Li Y, Yang D (2015) A review of the genus Toxorhina Loew from China, with descriptions of three new species (Diptera, Limoniidae, Limoniinae). ZooKeys 480: 59-80. doi: 10.3897/zookeys.480.7526

\begin{abstract}
The genus Toxorhina Loew from China is reviewed. Seven species belonging to the subgenus Ceratocheilus Wesche are recognized, of which three species, T. (C.) huanglica sp. n., T. (C.) omnifusca sp. n. and T. (C.) univirgata sp. n., are described as new to science, $T$. (C.) fuscolimbata Alexander is recorded from China for the first time, and three known species are redescribed and illustrated.
\end{abstract}

\section{Keywords}

China, Diptera, Limoniidae, new species, Toxorhina

\section{Introduction}

The genus Toxorbina was erected by Loew in 1850. Its detailed features for the recognition are given by Osten Sacken (1869) and Alexander (1947). The genus is well defined by the elongate rostrum which is longer than head and thorax combined together. The genera Elephantomyia Osten Sacken and Helius Lepeletier \& Serville have same feature (mouth parts of the genus Geranomyia Haliday are strongly elongate, but 
rostrum short (Podenas and Gelhaus 2007)), but Toxorhina can be easily distinguished from them by the antenna with 12 or less segments and with long hairs on outer two segments only (Fig. 1: d), the wing with much reduced venation, and the legs with profoundly bifid hairs (Fig. 3: a). The genus Toxorhina is divided into three subgenera: Ceratocheilus Wesche, 1910, Toxorhina (s. str.) and Eutoxorhina Alexander, 1934. The subgenus Ceratocheilus is easily distinguished from the other two subgenera by the wing with two branches of Rs reaching the margin (Fig. 1: d). In the subgenera Toxorhina and Eutoxorhina, the wing has a single branch of Rs reaching the margin.

The genus Toxorhina is widely distributed in the world except the Palaearctic Region. It has 148 known species, of which 2 species are from the Nearctic Region, 37 species are from the Neotropic Region, 36 species are from the Afrotropical Region, 33 species are from the Oriental Region, and 40 species are from the Australasian (Oceanian) Region. The subgenus Ceratocheilus has 77 known species, of which 12 species are from the Neotropic Region, 24 species are from the Afrotropical Region, 17 species are from the Oriental Region, and 24 species are from the Australasian (Oceanian) Region (Oosterbroek 2014).

This paper redescribed and illustrated three known species and one new record from China, including detailed descriptions and illustrations of male of $T$. (C.) tinctipennis, T. (C.) taiwanicola for the first time. In addition, three new species, $T$. $(C$.) huanglica sp. n., T. (C.) omnifusca sp. n. and T. (C.) univirgata sp. n., are described and illustrated.

\section{Material and methods}

The specimens were studied and illustrated with ZEISS Stemi 2000-c stereo microscope. Details of coloration were mainly checked in specimens immersed in $75 \%$ ethyl alcohol $\left(\mathrm{C}_{2} \mathrm{H}_{5} \mathrm{OH}\right)$. Genitalic preparations were made by macerating the apical portion of the abdomen in cold $10 \% \mathrm{NaOH}$ for $12-15$ hours. After examination it was transferred to fresh glycerin $\left(\mathrm{C}_{3} \mathrm{H}_{8} \mathrm{O}_{3}\right)$ and stored in a micro vial pinned below the specimen. Type specimens of $T$. (C.) formosensis, $T$. (C.) taiwanicola and $T$. (C.) tinctipennis are deposited in USNM (the National Museum of Natural History, Smithsonian Institution, Washington D.C., USA). The other studied specimens, including type specimens of $T$. (C.) huanglica sp. n., T. (C.) omnifusca sp. n. and T. (C.) univirgata sp. n., are deposited in CAU (the Entomological Museum of China Agricultural University, Beijing, China).

The morphological terminology mainly follows McAlpine (1981), and the venation is described after Alexander and Byers (1981). Terminology of male hypopygium changes according to Ribeiro (2006): lobe of gonostylus = inner gonostylus, clasper of gonostylus = outer gonostylus. The following abbreviations in figures are used: $\operatorname{tg} 9 / 10$ = tergite nine/ten, st 9 = sternite nine, goncx = gonocoxite, gonst $=$ gonostylus, $\mathrm{c}$ gonst = clasper of gonostylus, l gonst $=$ lobe of gonostylus, aed = aedeagus, interb = interbase, cerc $=$ cercus, hyp vlv = hypogynial valve. 


\section{Taxonomy}

\section{Key to species of subgenus Ceratocheilus from Oriental Region}

$1 \quad$ Wing with darkened seams along several veins (Fig. 3d) ............................. 2

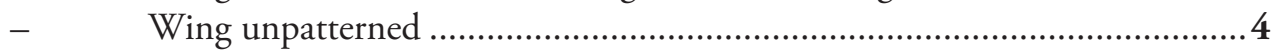

2 Wing with basal section of $\mathrm{CuA}_{1}$ beyond fork of $\mathrm{M}$ (Fig. 3d)

T. fuscolimbata Alexander, 1967 (China; India)

Wing with basal section of $\mathrm{CuA}_{1}$ at or close to fork of $\mathrm{M}$...... .3

Size medium (wing length $5.0 \mathrm{~mm}$ ); legs with coxae and trochanters yellow, fore pair weakly darkened; haltere pale yellow (Alexander 1956).

T. capnitis Alexander, 1956 (Thailand)

- $\quad$ Size relatively large (wing length $6.5 \mathrm{~mm}$ ), legs with coxae ochreous, trochanters blackish; haltere white (Edwards 1926)

T. majus (Edwards, 1926) (Malaysia)

Pleuron with conspicuous darkened stripe(s) (Figs 3a, 5a, 13a) ...................5

Pleuron uniformly concolorous or with darker or paler region, without conspicuous stripe ....

Wing with $\mathrm{R}_{2+3}$ ending before end of basal section of $\mathrm{R}_{4+5}, \mathrm{R}_{2+3}$ nearly perpendicular at origin (Alexander 1929)

T. romblonensis (Alexander, 1929) (Philippines)

Wing with $\mathrm{R}_{2+3}$ ending at or beyond end of basal section of $\mathrm{R}_{4+5}, \mathrm{R}_{2+3}$ not as above

Abdomen bicolored (Fig. 5a); gonocoxite of male hypopygium with a blunt lobe near base (Fig. 6a-b)

T. huanglica sp. n. (China)

Abdomen not as above; gonocoxite of male hypopygium without lobe near base.

Male hypopygium with rods of aedeagus short (Alexander 1962, 1970)

T. monostyla Alexander, 1962 (India)

Wing with basal section of $\mathrm{CuA}_{1}$ beyond fork of $\mathrm{M}$.

Male hypopygium with rods of aedeagus long (Fig. 14a-b)

Wing with basal section of $\mathrm{CuA}_{1}$ before or close to fork of $\mathrm{M}$ . .9

Antenna black throughout; rostrum shorter than wing or remainder of body (Alexander 1967; Alexander 1970) T. bistyla Alexander, 1967 (India) Antenna black with scape obscure yellow; rostrum longer than wing or remainder of body (Brunetti 1918; Alexander 1936; Joseph 1979)

$$
\text { T. brevifrons (Brunetti, 1918) (India) }
$$

10 Abdomen light brown, hinder half of segments distinctly darker

T. latifrons (Brunetti, 1918) (Malaysia)

11 Male hypopygium with rods of aedeagus long .......................................12

Male hypopygium with rods of aedeagus short .........................................14 
12 Rostrum longer than wing (Alexander 1967) T. fulvicolor Alexander, 1967 (India)

- $\quad$ Rostrum shorter than wing 13

13 Wing with $\mathrm{R}_{2+3}$ short, with a rather strong double curve; male hypopygium with gonostylus rather slender and mainly pale, with a long black tooth in middle at right angles to main axis (Edwards 1933)

T. contractifrons (Edwards, 1933) (Malaysia)

- Wing with $\mathrm{R}_{2+3}$ long, gently sinuous (Fig. 1d); male hypopygium with gonostylus stout and entirely blackened, outer lateral angle with a slender rod (Fig. 2) T. formosensis (Alexander, 1928) (China)

14 Gonocoxite of male hypopygium without lobe near base ..........................15 Gonocoxite of male hypopygium with a blunt lobe near base .....................16

15 Wing with $\mathrm{Sc}_{1}$ ending near middle of Rs; gonocoxite of male hypopygium with two dense areas of setae beyond middle and near apex (Alexander 1962; Alexander 1970) T. luteibasis Alexander, 1962 (India)

- Wing with $\mathrm{Sc}_{1}$ just before origin of Rs (Fig. $7 \mathrm{~d}$ ); gonocoxite of male hypopygium not as above T. omnifusca sp. n. (China)

16 Pleuron uniformly brownish black or black .........................................17

- $\quad$ Pleuron dark brown with ventral region paler ...........................................18

17 Wing with a strong brown suffusion, $\mathrm{R}_{2+3}$ ending beyond or close to end of basal section of $\mathrm{R}_{4+5}$ (Fig. 11e).... T. tinctipennis (Alexander, 1930) (China) Wing subhyaline with base more yellowed, $\mathrm{R}_{2+3}$ ending before end of basal section of $\mathrm{R}_{4+5}$ (Alexander 1966) .......T. tuberifera Alexander, 1966 (India)

18 Male hypopygium with gonostylus as long as gonocoxite (Alexander 1967) ... T. simplicistyla Alexander, 1967 (India)

- $\quad$ Male hypopygium with gonostylus conspicuously shorter than gonocoxite... 19

19 Wing with $\mathrm{R}_{2+3}$ ending beyond end of basal section of $\mathrm{R}_{4+5}$; gonostylus of male hypopygium with a spine near basal third (Alexander 1936; Alexander 1970) .......................................... T. mesorhyncha Alexander, 1936 (India)

- Wing with $\mathrm{R}_{2+3}$ ending before end of basal section of $\mathrm{R}_{4+5}$ (Fig. 9e); gonostylus of male hypopygium with a spine near middle (Fig. 10a-b).

T. taiwanicola (Alexander, 1923) (China)

\section{Toxorbina (Ceratocheilus) formosensis Alexander, 1928}

Figs $1-2$

Ceratocheilus formosensis Alexander 1928: 479. Type locality: Mt. Rantaizan, China (Taiwan).

Diagnosis. Rostrum shorter than wing. Prescutum brown with three broad dark brown stripes. Pleuron generally dark brown. Wing tinged pale grey; $\mathrm{R}_{2+3}$ ending beyond end of basal section of $\mathrm{R}_{4+5}$, basal section of $\mathrm{CuA}_{1}$ before fork of $\mathrm{M}$. Abdomen 


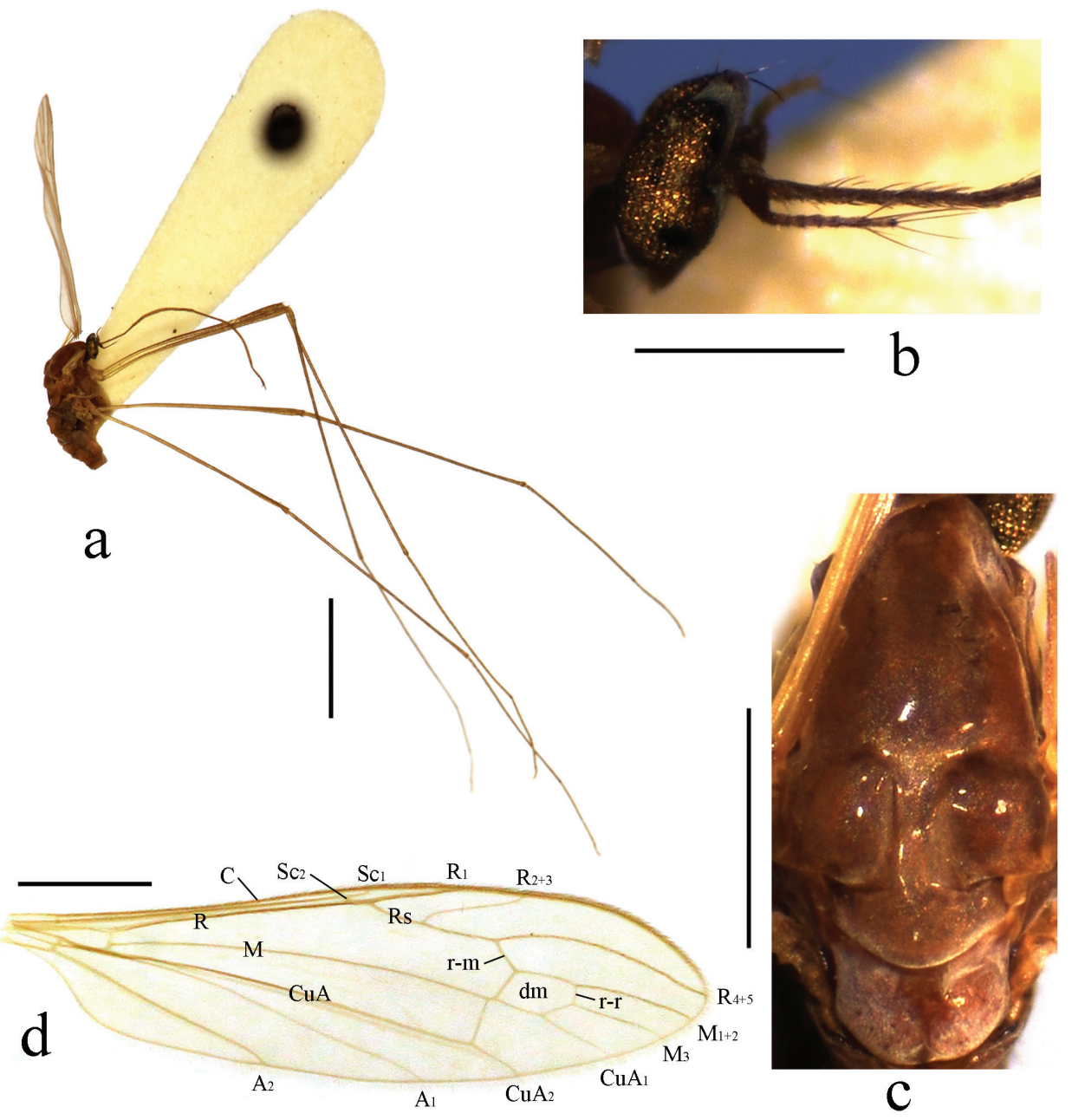

Figure I. Toxorhina (Ceratocheilus) formosensis Alexander, 1928. Holotype. a Male habitus, lateral view b Head, lateral view c Thorax, dorsal view d Wing. Scale bar: $\mathbf{a}=2.0 \mathrm{~mm} ; \mathbf{b}=0.5 \mathrm{~mm} ; \mathbf{c}=0.5 \mathrm{~mm} ; \mathbf{d}=1.0 \mathrm{~mm}$.

Generally brown to dark brown. Gonostylus stout and entirely blackened, outer lateral angle with a slender rod. Rods of aedeagus long.

Description. Male. Body length $4.2 \mathrm{~mm}$, wing length $5.2 \mathrm{~mm}$, rostrum length $4.0 \mathrm{~mm}$.

Head (Fig. 1b). Brownish black. Hairs on head black. Antenna length $0.4-0.5 \mathrm{~mm}$, black. Pedicel enlarged and nearly globose. First flagellomere subconical; remaining flagellomeres cylindrical, each flagellomere longer and slenderer than previous one, terminal two flagellomeres longest with several long hairs. Rostrum black with black hairs.

Thorax. Generally brown to dark brown. Pronotum brown. Prescutum brown with three broad dark brown stripes. Scutum dark brown with middle area paler. Scutellum 


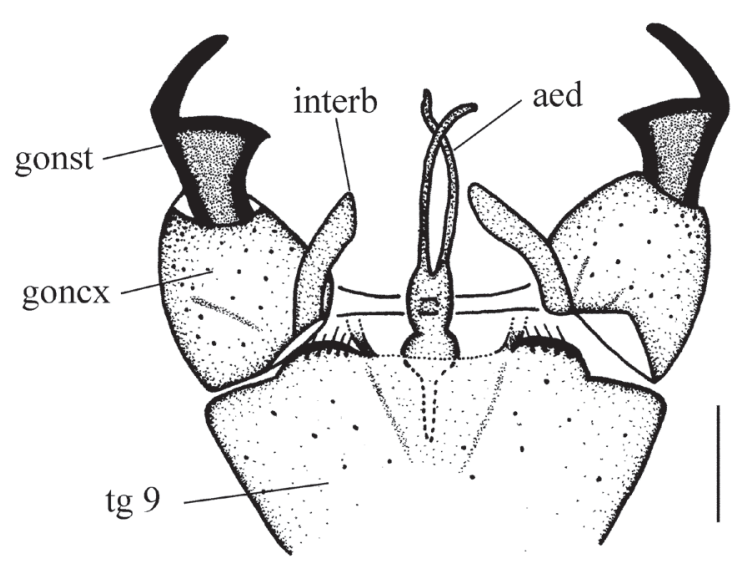

Figure 2. Toxorhina (Ceratocheilus) formosensis Alexander, 1928. Holotype. Male hypopygium, dorsal view. Scale bar: $0.2 \mathrm{~mm}$.

and mediotergite brown (Fig. 1c). Pleuron (Fig. 1a) generally dark brown. Hairs on thorax dark brown. Coxae and trochanters brownish yellow; femora dark brown with bases paler; tibiae and tarsi dark brown. Wing (Fig. 1d) tinged pale grey; veins pale brown. Venation: $\mathrm{Sc}_{1}$ ending nearly at origin of $\mathrm{Rs}, \mathrm{Sc}_{2}$ near its tip; $\mathrm{R}_{2+3}$ ending beyond end of basal section of $\mathrm{R}_{4+5}$; basal section of $\mathrm{CuA}_{1}$ before fork of $\mathrm{M}$; $\mathrm{A}_{1}$ curved relatively smooth. Haltere length $0.7 \mathrm{~mm}$, pale brownish yellow with knob darker.

Abdomen (Fig. 1a). Generally brown to dark brown. Hairs on abdomen dark brown.

Hypopygium (Fig. 2). Gonocoxite conical, relatively short and stout. Gonostylus stout and entirely blackened, outer lateral angle with a slender rod. Interbase compressed and slightly curved to aedeagus, tip blunt. Aedeagus with tip divergent, rods long filiform.

Female. Unknown.

Specimens examined. Holotype male (USNM), China: Taiwan, Mt. Rantaizan $(1829 \mathrm{~m}), 1927 . V I .3$, Syuti Issiki. (One wing and hypopygium are mounted on a similarly labeled microscope slide. Two fore legs and two mid legs are still attached to the dry mounted body, and two hind legs are absent.)

Distribution. China (Taiwan).

Remarks. For description and illustration of this species, also see Alexander (1928).

Toxorbina (Ceratocheilus) fuscolimbata Alexander, 1967

Figs 3-4

Toxorbina (Ceratocheilus) fuscolimbata Alexander 1967: 185. Type locality: Hkayam Boum, Manipur, Assa, India.

Diagnosis. Rostrum shorter than wing. Prescutum brownish yellow with three broad and nearly confluent brownish black stripes. Pleuron yellow with two black stripes. 

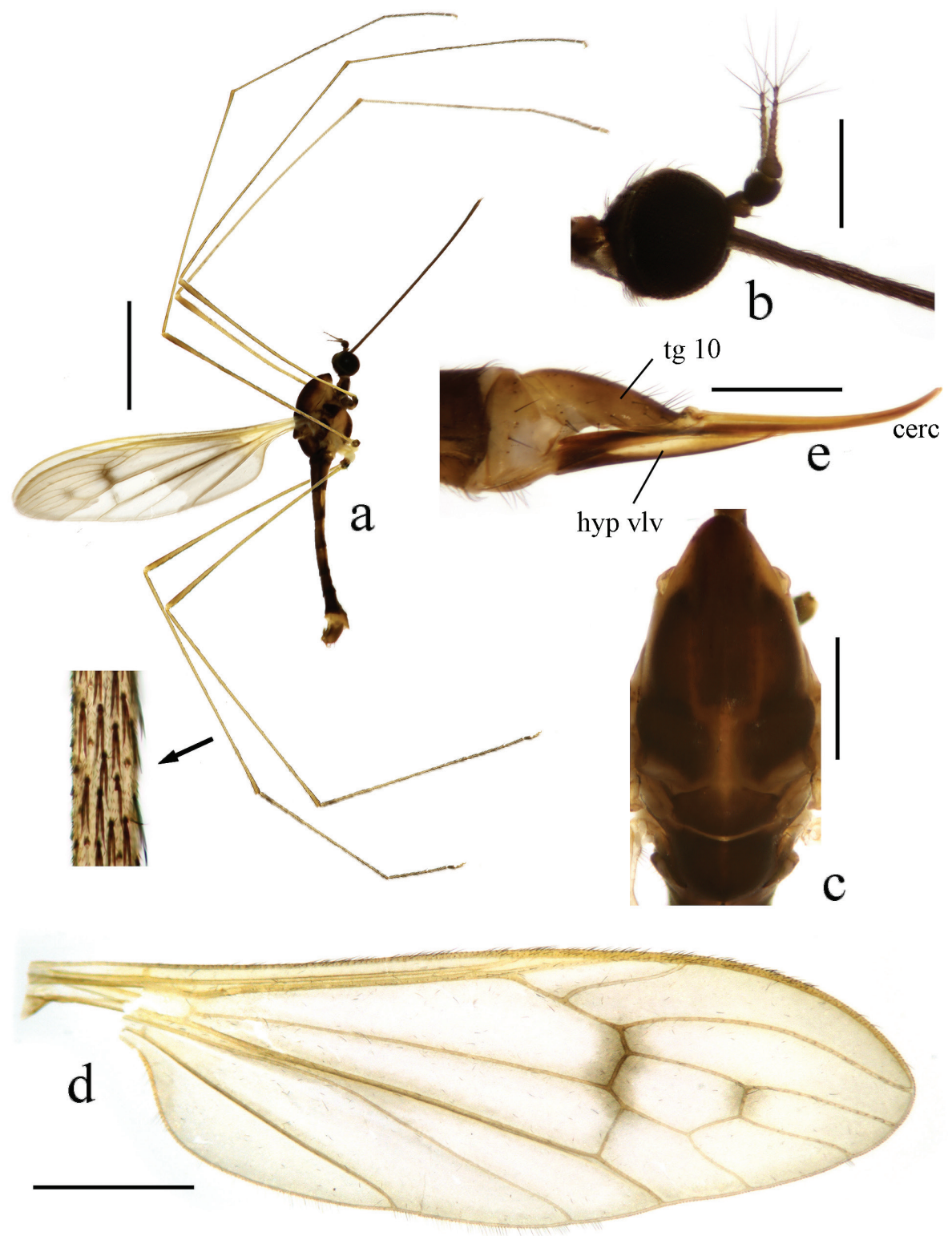

Figure 3. Toxorhina (Ceratocheilus) fuscolimbata Alexander, 1967. a Male habitus, lateral view b Head, lateral view c Thorax, dorsal view $\mathbf{d}$ Wing e Female hypopygium, lateral view. Scale bar: $\mathbf{a}=2.0 \mathrm{~mm}$; $\mathbf{b}=0.5 \mathrm{~mm} ; \mathbf{c}=0.5 \mathrm{~mm} ; \mathbf{d}=1.0 \mathrm{~mm} ; \mathbf{e}=0.3 \mathrm{~mm}$.

Wing tinged pale grey, black seams along cord and $\mathrm{m}$-m and paler seam over base of $\mathrm{CuA} ; \mathrm{R}_{2+3}$ ending beyond end of basal section of $\mathrm{R}_{4+5}$, basal section of $\mathrm{CuA}_{1}$ beyond fork of $\mathrm{M}$ and at one-third of cell $\mathrm{dm}$. Abdomen with sternites more or less bicolored. Male hypopygium with two pairs of gonostyl. Rods of aedeagus short. 

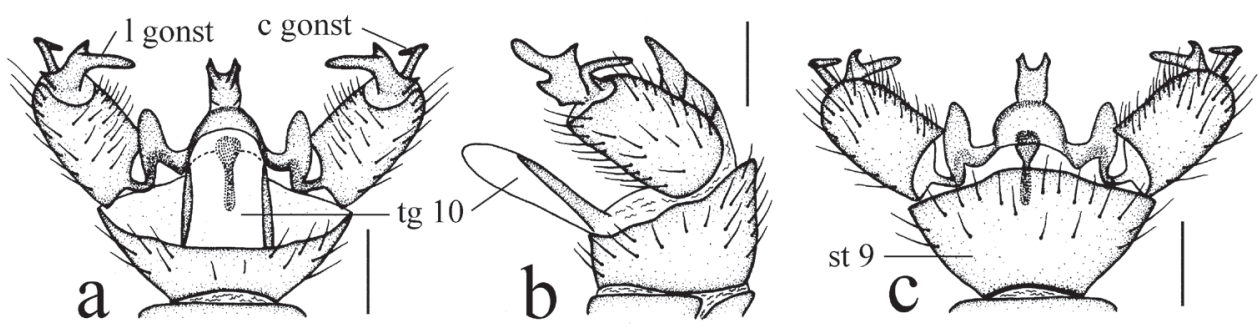

Figure 4. Toxorhina (Ceratocheilus) fuscolimbata Alexander, 1967. a Male hypopygium, dorsal view b Male hypopygium, lateral view c Male hypopygium, ventral view. Scale bar: a-c $=0.2 \mathrm{~mm}$.

Description. Male. Body length 5.0-5.5 mm, wing length 5.5-6.0 mm, rostrum length $3.5 \mathrm{~mm}$.

Head (Fig. 3b). Brownish black. Hairs on head black. Antenna length 0.5-0.6 $\mathrm{mm}$. Scape brownish black; pedicel black; flagellomeres brownish black. Pedicel enlarged and nearly globose. First flagellomere subconical; remaining flagellomeres cylindrical, each flagellomere longer and slenderer than previous one, terminal two flagellomeres longest with several long hairs. Rostrum brownish black with black hairs.

Thorax. Pronotum brownish black. Prescutum brownish yellow with three broad and nearly confluent brownish black stripes. Scutum brownish black with middle area paler, each lobe with a light yellow spot. Scutellum and mediotergite brownish black (Fig. 3c). Pleuron (Fig. 3a) yellow with two black stripes, upper one extending from cervical region to mediotergite, lower one extending from fore coxa to middle coxa. Hairs on thorax black. Fore coxa brownish black, middle and hind coxae pale yellow; trochanters brownish black; femora yellow to brownish yellow with tips darker; tibiae and tarsi brownish yellow. Hairs on legs black. Wing (Fig. 3d) tinged pale grey, black seams along cord and $\mathrm{m}-\mathrm{m}$ and paler seam over base of $\mathrm{CuA}$; veins pale brown, darker at $\mathrm{CuA}$ and $\mathrm{A}_{2}$ and in clouded areas. Venation: $\mathrm{Sc}_{1}$ ending a very short distance beyond origin of $\mathrm{Rs}, \mathrm{Sc}_{2}$ a greater distance before origin of $\mathrm{Rs} ; \mathrm{R}_{2+3}$ ending beyond end of basal section of $\mathrm{R}_{4+5}$; basal section of $\mathrm{CuA}_{1}$ beyond fork of $\mathrm{M}$ and at one-third of cell $\mathrm{dm}$; $\mathrm{A}_{1}$ curved suddenly at middle, basal half nearly straight. Haltere length $0.8-0.9 \mathrm{~mm}$, white.

Abdomen (Fig. 3a). Tergites dark brown. Sternites brownish yellow with caudal $1 / 3$ to $1 / 2$ dark brown, sometomes uniformly dark brown. Segments six to eight uniformly dark brown to brownish black. Segment nine yellow to brownish yellow. Hairs on abdomen brownish black.

Hypopygium (Fig. 4). Generally dark brown. Gonocoxite cylindrical. Clasper of gonostylus slender and rod-shaped, curved ventrally and inwards, tip acute. Lobe of gonostylus with two stout spines near base. Interbase oval. Aedeagus with tip divergent, rods short.

Female. Body length 6.0-7.0 mm, wing length 5.5-6.0 mm, rostrum length 3.5$3.8 \mathrm{~mm}$. Similar to male. But antenna obviously longer, each flagellomere subequal. Tenth tergite pale brown. Cercus dark brownish yellow. Hypogynial valve brownish 
yellow with base brownish black. Tip of hypogynial valve reaching at 2/5 of cercus (Fig. 4e).

Specimens examined. 2 males 2 females (CAU), China: Guangxi, Baise, Mt. Cenwanglao $\left(24^{\circ} 29^{\prime} 12^{\prime \prime} \mathrm{N}, 106^{\circ} 20^{\prime} 55^{\prime \prime E}, 1300 \mathrm{~m}\right)$, 2013.VII.29, Yuting Dai \& Mengchao Tan. 4 males (CAU), China: Yunnan, Gongshan, Dulongjiang (27\%40'32"N, 98²0'3"E, 1542 m), 2013.VII.1, Wei Zhang. 1 male (CAU), China: Xizang, Yigong (2300 m), 1978.VII.29, Fasheng Li.

Distribution. China (Guangxi, Yunnan, Xizang); India.

Remarks. This species is recorded from China for the first time. For description and illustration of this species, also see Alexander $(1967,1970)$.

\section{Toxorbina (Ceratocheilus) huanglica sp. n.}

http://zoobank.org/F286A8EA-9BD6-4632-AADB-82D42E460502

Figs 5-6

Diagnosis. Rostrum shorter than wing. Prescutum brownish yellow with three broad dark brown stripes. Pleuron dark yellow with two black stripes. Wing tinged pale brown; $\mathrm{R}_{2+3}$ ending at or slightly beyond end of basal section of $\mathrm{R}_{4+5}$, basal section of $\mathrm{CuA}_{1}$ at or slightly before fork of $\mathrm{M}$. Abdomen bicolored. Gonostylus with a stout spine near middle. Rods of aedeagus relatively short.

Description. Male. Body length 5.0-5.5 mm, wing length 4.5-5.0 mm, rostrum length $3.5 \mathrm{~mm}$.

Head (Fig. 5b). Brownish black. Hairs on head black. Antenna length 0.6-0.7 $\mathrm{mm}$. Scape and pedicel dark brown; flagellomeres brown. Pedicel enlarged and nearly globose. First flagellomere subconical; remaining flagellomeres cylindrical, each flagellomere longer and slenderer than previous one, terminal two flagellomeres longest with several long hairs. Rostrum brownish black with black hairs.

Thorax. Pronotum dark brown. Prescutum brownish yellow with three broad dark brown stripes. Scutum dark brown with middle area paler, each lobe with a light yellow spot. Scutellum brown. Mediotergite dark brown to brownish black (Fig. 5c). Pleuron (Fig. 5a) dark yellow with two black stripes, upper one extending from cervical region to mediotergite, lower one extending from fore coxa to middle coxa. Hairs on thorax brownish black. Fore and middle coxa brownish yellow, hind coxae pale yellow; trochanters brownish black; femora brownish yellow with tips darker; tibiae and tarsi dark brown. Hairs on legs black. Wing (Fig. 5d) tinged pale brown; veins pale brown, darker at cord, $\mathrm{m}-\mathrm{m}$ and basal section of $\mathrm{M}_{3}$. Venation: $\mathrm{Sc}_{1}$ a short distance beyond origin of $\mathrm{Rs}$, $\mathrm{Sc}_{2}$ a slightly greater distance before origin of $\mathrm{Rs} ; \mathrm{R}_{2+3}$ ending at or slightly beyond end of basal section of $\mathrm{R}_{4+5}$; basal section of $\mathrm{CuA}_{1}$ at or slightly before fork of $\mathrm{M} ; \mathrm{A}_{1}$ curved suddenly at middle, basal half nearly straight. Haltere length $0.7-0.8 \mathrm{~mm}$, pale yellow.

Abdomen (Fig. 5a). Tergites and sternites yellow with caudal halves brownish black. Segments six to eight uniformly brownish black. Tergite nine yellow. Sternite nine brownish yellow to brown. Hairs on abdomen brownish black. 

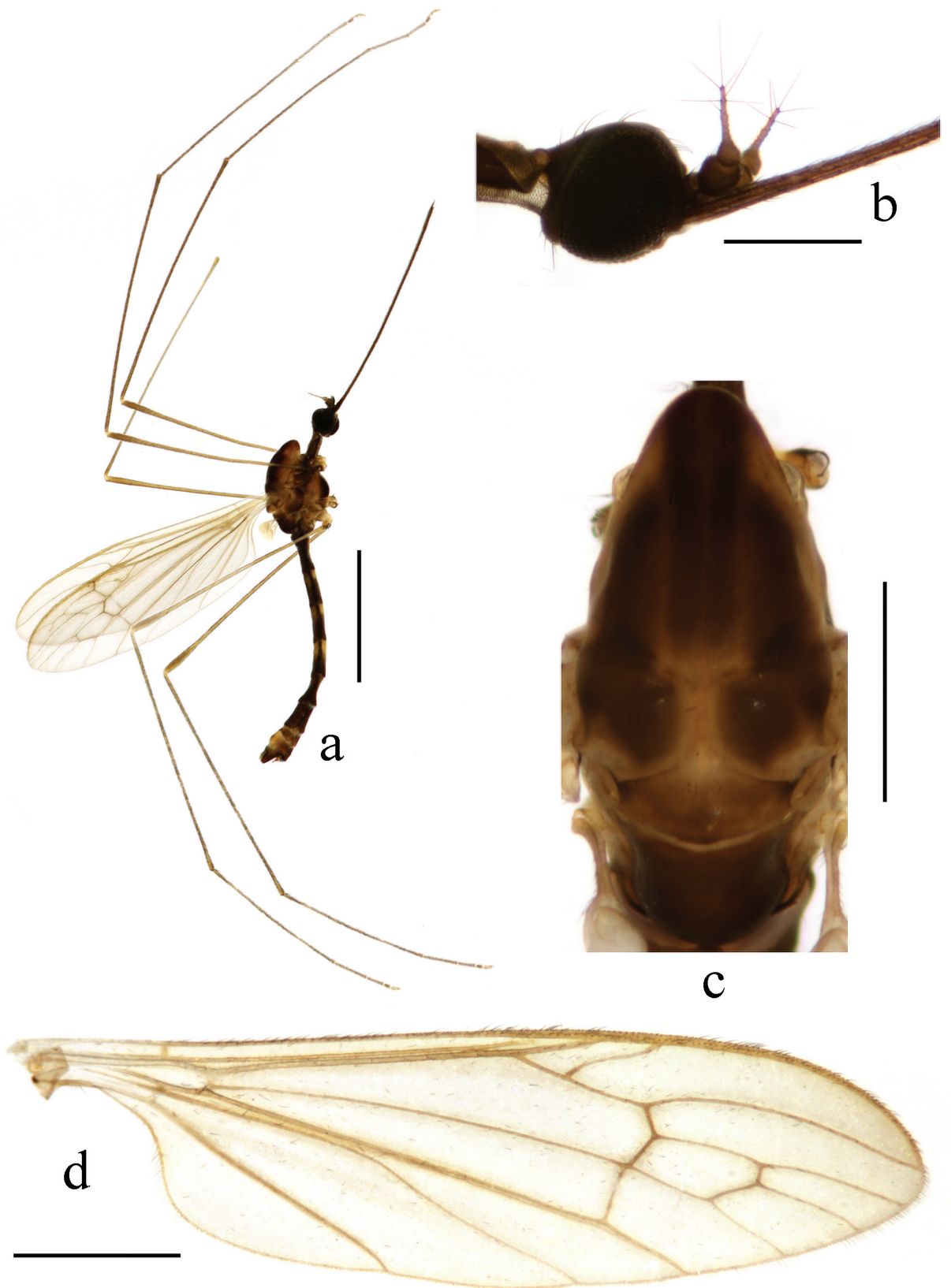

Figure 5. Toxorbina (Ceratocheilus) huanglica sp. n. a Male habitus, lateral view b Head, lateral view c Thorax, dorsal view $\mathbf{d}$ Wing. Scale bar: $\mathbf{a}=2.0 \mathrm{~mm} ; \mathbf{b}=0.5 \mathrm{~mm} ; \mathbf{c}=0.5 \mathrm{~mm} ; \mathbf{d}=1.0 \mathrm{~mm}$.

Hypopygium (Fig. 6). Generally dark brown. Gonocoxite conical, dorsal face with several setae and a blunt lobe near base, this lobe with numerous setae. Gonostylus with a stout spine near middle, basal half stout with a longitudinal groove. Interbase rod-shaped. Aedeagus with tip divergent, rods relatively short. 

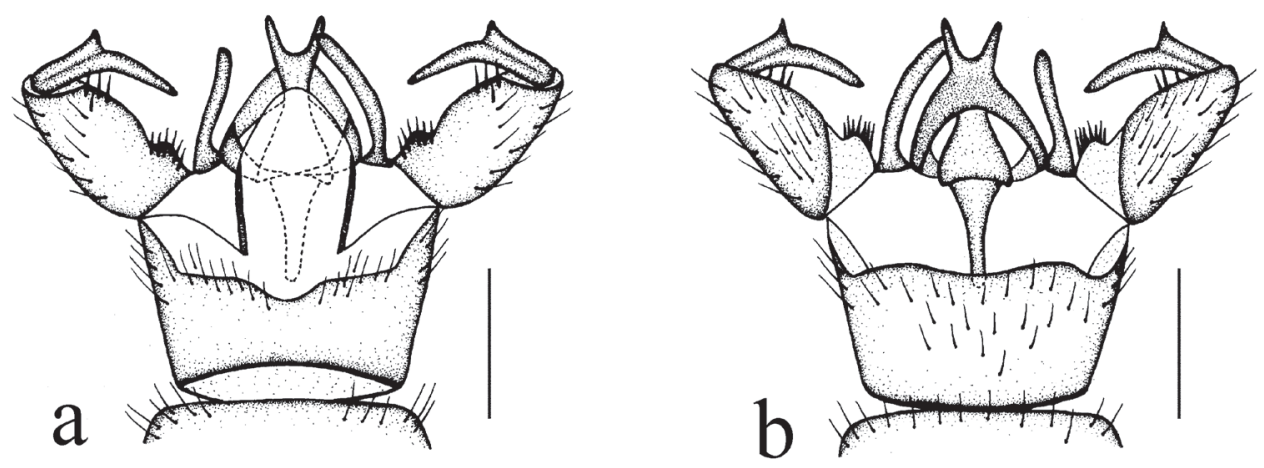

Figure 6. Toxorhina (Ceratocheilus) huanglica sp. n. a Male hypopygium, dorsal view b Male hypopygium, ventral view. Scale bar: $\mathbf{a}-\mathbf{b}=0.2 \mathrm{~mm}$.

Female. Unknown.

Type material. Holotype male (CAU), China: Yunnan, Lvchun, Mt. Huanglian, Qimaba (2248'36"N, 102¹4'24"E, $1012 \mathrm{~m})$, 2013.VI.11, Jinying Yang (light trap). Paratypes: 4 males (CAU), same data as holotype.

Distribution. China (Yunnan).

Etymology. The species is named after the type locality Mt. Huanglian.

Remarks. This new species is somewhat similar to $T$. (C.) fuscolimbata in having the similar body color, but it can be easily distinguished from the latter by the wing without conspicuous black seams and with basal section of $\mathrm{CuA}_{1}$ at or slightly before fork of M (Fig. 5d), the male hypopygium with one pair of gonostyl, the gonocoxite with a blunt lobe near base, and the interbase rod-shaped (Fig. 6). In T. (C.) fuscolimbata, the wing has the black seams along several veins, the basal section of $\mathrm{CuA}_{1}$ is beyond fork of $\mathrm{M}$ (Fig. 3d), the male hypopygium has two pairs of gonostyl, the gonocoxite has no lobe near base, and the interbase is oval (Fig. 4).

\section{Toxorbina (Ceratocheilus) omnifusca sp. n.}

http://zoobank.org/F9AB2E53-3F90-49B6-BCFC-E1DC0069B28F Figs $7-8$

Diagnosis. Rostrum shorter than wing. Prescutum dark brown. Pleuron dark brown with central region slightly darker. Wing tinged pale brown; $\mathrm{R}_{2+3}$ ending at or slightly beyond end of basal section of $\mathrm{R}_{4+5}$, basal section of $\mathrm{CuA}_{1}$ at or slightly before fork of M. Abdomen dark brown with with segments six to eight slightly darker. Male hypopygium with two pairs of gonostyl. Rods of aedeagus relatively short.

Description. Male. Body length $6.0 \mathrm{~mm}$, wing length $5.5 \mathrm{~mm}$, rostrum length $3.5 \mathrm{~mm}$.

Head (Fig. 7b). Brownish black. Hairs on head brownish black. Antenna length 0.6$0.7 \mathrm{~mm}$. Scape and pedicel dark brown; flagellomeres brown to brownish yellow. Pedicel enlarged and nearly globose. First flagellomere subconical; remaining flagellomeres 

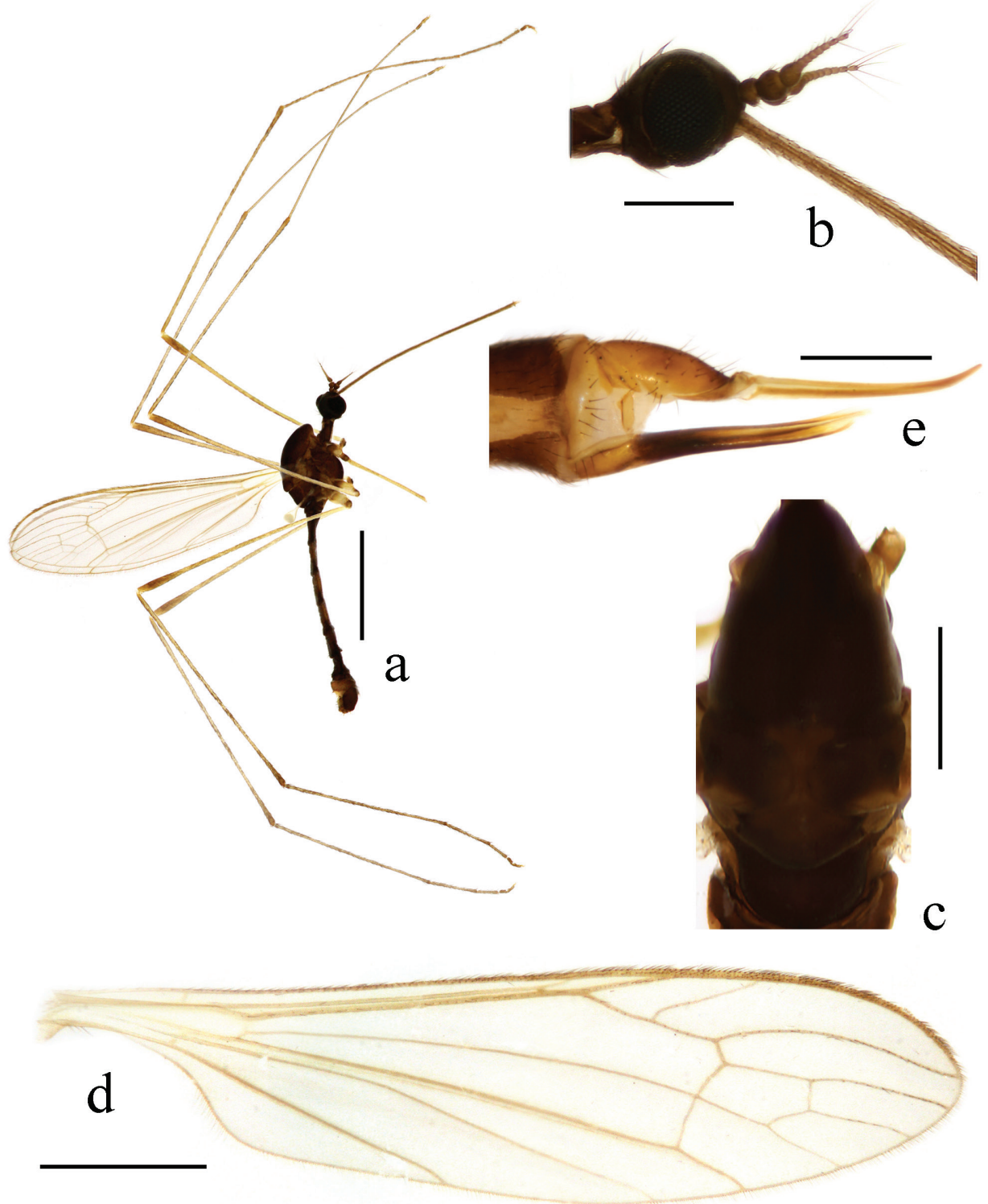

Figure 7. Toxorhina (Ceratocheilus) omnifusca sp. n. a Male habitus, lateral view b Head, lateral view c Thorax, dorsal view $\mathbf{d}$ Wing e Female hypopygium, lateral view. Scale bar: $\mathbf{a}=2.0 \mathrm{~mm} ; \mathbf{b}=0.5 \mathrm{~mm}$; $\mathbf{c}=0.5 \mathrm{~mm} ; \mathbf{d}=1.0 \mathrm{~mm} ; \mathbf{e}=0.4 \mathrm{~mm}$.

cylindrical, each flagellomere longer and slenderer than previous one, terminal two flagellomeres longest with several long hairs. Rostrum brownish yellow with brown hairs.

Thorax. Generally dark brown. Pronotum and prescutum dark brown. Scutum dark brown with middle area paler, each lobe with a paler spot. Scutellum brown with borders darker. Mediotergite dark brown (Fig. 7c). Pleuron (Fig. 7a) dark brown with central region 

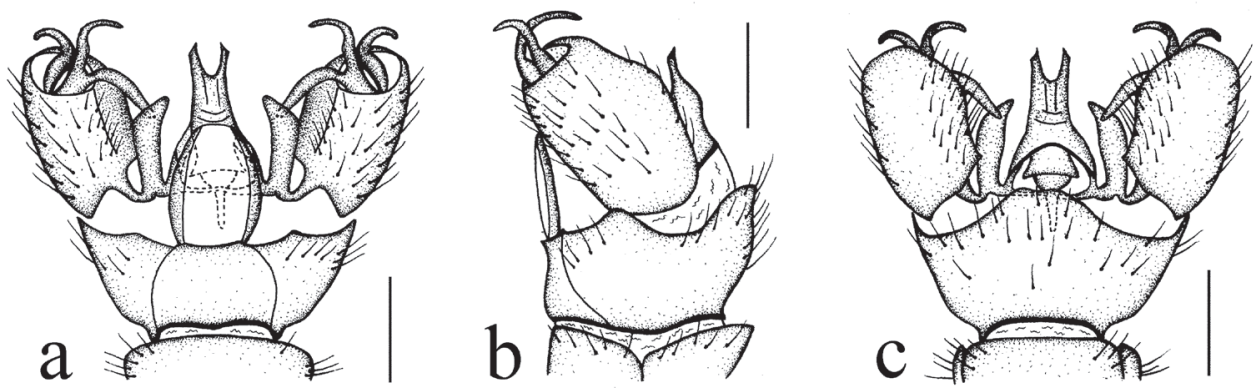

Figure 8. Toxorhina (Ceratocheilus) omnifusca sp. n. a Male hypopygium, dorsal view b Male hypopygium, lateral view c Male hypopygium, ventral view. Scale bar: $\mathbf{a}-\mathbf{c}=0.2 \mathrm{~mm}$.

slightly darker. Hairs on thorax dark brown. Coxae yellow to brownish yellow; trochanters brown; femora brownish yellow with bases yellow and tips pale brown; tibiae brownish yellow with tips pale brown; tarsi brownish yellow. Hairs on legs brown. Wing (Fig. 7d) tinged pale brownish yellow; veins brownish yellow. Venation: $\mathrm{Sc}_{1}$ just brfore origin of $\mathrm{Rs}$, $\mathrm{Sc}_{2}$ near its tip; $\mathrm{R}_{2+3}$ ending beyond end of basal section of $\mathrm{R}_{4+5}$; basal section of $\mathrm{CuA}_{1}$ at fork of $\mathrm{M}$; $\mathrm{A}_{1}$ curved suddenly at middle, basal half straight. Haltere length $0.8 \mathrm{~mm}$, white.

Abdomen (Fig. 7a). Dark brown with segments six to eight slightly darker. Hairs on abdomen dark brown.

Hypopygium (Fig. 8). Generally brown to dark brown. Gonocoxite cylindrical. Clasper of gonostylus slender and rod-shaped, curved dorsally and outwards, tip acute. Lobe of gonostylus divided into two branches: outer one slender, curved ventrally and inwards; inner one relatively stout, strongly curved inwards. Interbase nearly oval, tip curved inwards. Aedeagus with tip divergent, rods relatively short.

Female. Body length $8.5 \mathrm{~mm}$, wing length $6.5 \mathrm{~mm}$, rostrum length $4.0 \mathrm{~mm}$. Similar to male. Abdomen uniformly brown except hypopygium. Tenth tergite dark yellow to brownish yellow. Cercus brownish yellow with base paler. Hypogynial valve brownish yellow to brown with base yellow and middle area darker. Tip of hypogynial valve reaching just beyond middle of cercus (Fig. 7e).

Type material. Holotype male (CAU), China: Sichuan, Pingwu, Laohegou (32 $\left.18^{\prime} 33^{\prime \prime} \mathrm{N}, 104^{\circ} 42^{\prime} 45^{\prime} \mathrm{E}, 1100 \mathrm{~m}\right), 2012$.V.22, Yang Li \& Sipei Liu (light trap). Paratype: 1 female (CAU), same data as holotype.

Distribution. China (Sichuan).

Etymology. The specific epithet is an adjective and refers to the almost uniformly dark brown body (from Latin omnifuscus = omni- (adj., meaning “all”) + fuscus (adj., meaning "brown")).

Remarks. This new species is somewhat similar to $T$. (C.) tinctipennis in having the similar body color and venation of wing, but it can be easily distinguished from the latter by the male hypopygium with two pairs of gonostyl, the gonocoxite without lobe near base, and the interbase nearly oval (Fig. 8). In T. (C.) tinctipennis, the male hypopygium has one pair of gonostyl, the gonocoxite has a blunt lobe near base, and the interbase is rod-shaped (Fig. 12). 


\section{Toxorhina (Ceratocheilus) taiwanicola (Alexander, 1923)}

Figs $9-10$

Ceratocheilus taiwanicola Alexander 1923: 475. Type locality: Tattaka, China (Taiwan).

Diagnosis. Rostrum shorter than wing. Prescutum brownish yellow with three broad dark brown stripes. Pleuron dark brown with ventral region paler. Wing tinged pale grey; $\mathrm{R}_{2+3}$ ending before end of basal section of $\mathrm{R}_{4+5}$, basal section of $\mathrm{CuA}_{1}$ before fork of $\mathrm{M}$. Abdomen dark brown. Gonostylus with a relatively small spine near middle. Rods of aedeagus relatively short.

Description. Male. Body length 4.3-4.6 mm, wing length 4.5-5.4 mm, rostrum length $3.5 \mathrm{~mm}$.

Head (Fig. 9c). Dark brown. Hairs on head brownish black. Antenna length 0.4 $\mathrm{mm}$, dark brown. Pedicel enlarged and nearly globose. First flagellomere subconical; remaining flagellomeres cylindrical, each flagellomere longer and slenderer than previous one, terminal two flagellomeres longest with several long hairs. Rostrum brownish black with black hairs.

Thorax. Generally brownish yellow to brown. Pronotum dark brown. Prescutum brownish yellow with three broad dark brown stripes. Scutum, scutellum and mediotergite dark brown (Fig. 9d). Pleuron (Fig. 9a-b) dark brown with ventral region paler. Hairs on thorax dark brown. Coxa and trochanters pale brownish yellow; remainder of legs dark brown. Hairs on legs brownish black. Wing (Fig. 9e) tinged pale grey; veins pale brown. Venation: $\mathrm{Sc}_{1}$ ending a short distance beyond origin of $\mathrm{Rs}, \mathrm{Sc}_{2}$ a slightly greater distance before origin of $\mathrm{Rs} ; \mathrm{R}_{2+3}$ ending before end of basal section of $\mathrm{R}_{4+5}$; basal section of $\mathrm{CuA}_{1}$ before fork of $\mathrm{M} ; \mathrm{A}_{1}$ curved suddenly at middle, basal half straight. Haltere length $0.7-0.8 \mathrm{~mm}$, pale brownish yellow.

Abdomen (Fig. 9a-b). Dark brown, only hypopygium paler. Hairs on abdomen dark brown.

Hypopygium (Fig. 10). Generally brownish yellow. Gonocoxite conical, dorsal face with two or three setae near tip and a blunt lobe near base, this lobe with numerous setae. Gonostylus with a relatively small spine near middle. Interbase rod-shaped, tip slightly enlarged. Aedeagus with tip divergent, rods relatively short.

Female. Unknown.

Specimens examined. Holotype male (USNM), China: Taiwan, Tattaka (2250 m), 1921.VIII.18, Teiso Esaki. (One wing and hypopygium are mounted on a similarly labeled microscope slide. All six legs are still attached to the dry mounted body.) Other material: 1 male (CAU), China: Hainan, Ledong, Jianfengling, Mingfenggu (1842'32"N, 10849'41"E, 800 m), 2007.X.25, Xingyue Liu.

Distribution. China (Jiangxi, Taiwan, Hainan).

Remarks. Male hypopygium of this species is described in detail and illustrated for the first time. For description of this species, also see Alexander (1923). Alexander 

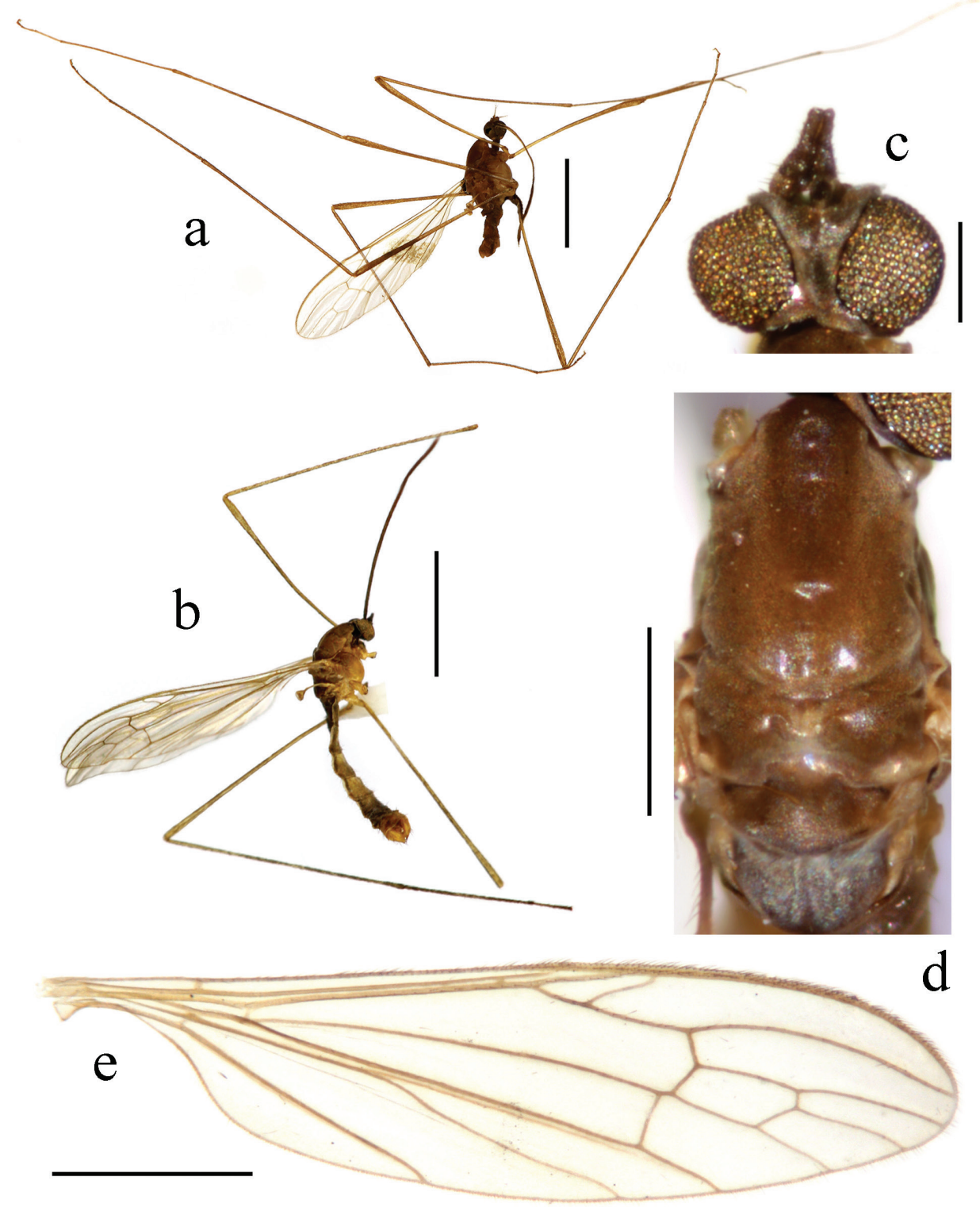

Figure 9. Toxorhina (Ceratocheilus) taiwanicola (Alexander, 1923). a Male habitus (holotype), lateral view $\mathbf{b}$ Male habitus, lateral view $\mathbf{c}$ Head, dorsal view $\mathbf{d}$ Thorax, dorsal view e Wing. Scale bar: $\mathbf{a}=2.0$ $\mathrm{mm} ; \mathbf{b}=2.0 \mathrm{~mm} ; \mathbf{c}=0.2 \mathrm{~mm} ; \mathbf{d}=0.5 \mathrm{~mm} ; \mathbf{e}=1.0 \mathrm{~mm}$.

(1923) described the basal section of $\mathrm{CuA}_{1}$ as "about one-fifth its length beyond the fork of M", whereas it is before the fork of $\mathrm{M}$ in both the holotype (Fig. 9a) and the specimen we examined (Fig. 9e). 

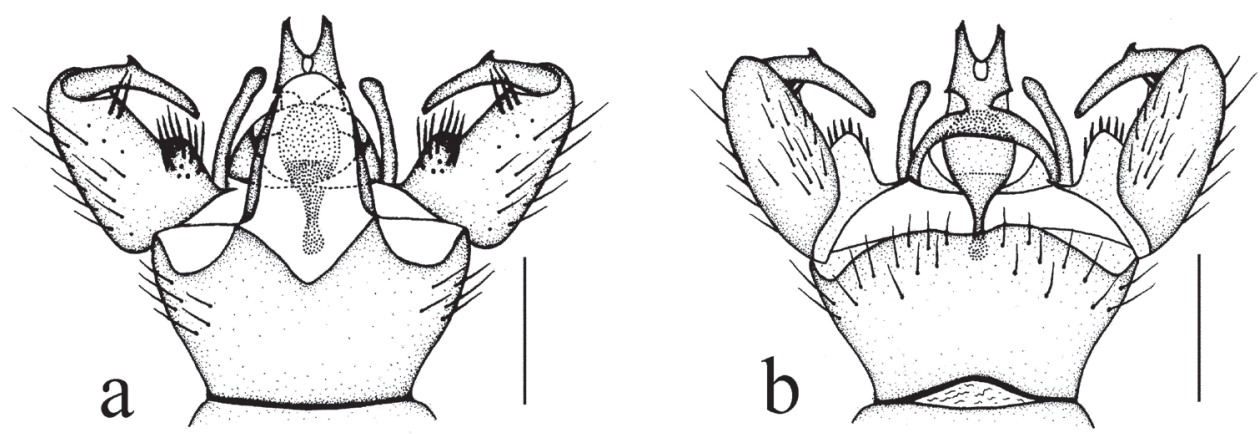

Figure 10. Toxorhina (Ceratocheilus) taiwanicola (Alexander, 1923). a Male hypopygium, dorsal view b Male hypopygium, ventral view. Scale bar: $\mathbf{a}-\mathbf{b}=0.2 \mathrm{~mm}$.

\section{Toxorbina (Ceratocheilus) tinctipennis (Alexander, 1930)}

Figs $11-12$

Ceratocheilus tinctipennis Alexander 1930: 75. Type locality: Mt. Ali (Arishan), China (Taiwan).

Diagnosis. Rostrum shorter than wing. Prescutum brownish black. Pleuron brownish black. Wing with a strong brown suffusion; $\mathrm{R}_{2+3}$ ending beyond or close to end of basal section of $\mathrm{R}_{4+5}$, basal section of $\mathrm{CuA}_{1}$ before or close to fork of $\mathrm{M}$. Abdomen dark brown with segments six to eight darker. Gonostylus with a very small spine near middle. Rods of aedeagus short.

Description. Male. Body length 5.0-6.0 mm, wing length 4.5-5.0 mm, rostrum length 3.0-3.5 mm.

Head (Fig. 11c). Dark brown. Hairs on head dark brown. Antenna length 0.6-0.7 $\mathrm{mm}$. Scape brown; pedicel and flagellomeres dark brown. Pedicel enlarged and nearly globose. First flagellomere subconical; remaining flagellomeres cylindrical, each flagellomere longer and slenderer than previous one, terminal two flagellomeres longest with several long hairs. Rostrum dark brown to brownish black with dark brown hairs.

Thorax. Generally dark brown to brownish black. Pronotum dark brown. Prescutum brownish black. Scutum dark brown with middle area slightly paler. Scutellum dark brown with borders brownish black to black. Mediotergite dark brown (Fig. 11d). Pleuron (Fig. 11a-b) brownish black. Hairs on thorax dark brown. Coxae brownish yellow; trochanters yellow; femora dark brown with bases paler; tibiae and tarsi dark brown to brownish black. Hairs on legs dark brown. Wing (Fig. 11e) with a strong brown suffusion; veins dark brown. Venation: $\mathrm{Sc}_{1}$ ending a short distance beyond origin of $\mathrm{Rs}, \mathrm{Sc}_{2}$ same or a slightly greater distance before origin of $\mathrm{Rs} ; \mathrm{R}_{2+3}$ ending beyond or close to end of basal section of $\mathrm{R}_{4+5}$; basal section of $\mathrm{CuA}_{1}$ before or close to fork of $\mathrm{M} ; \mathrm{A}_{1}$ curved suddenly at middle, basal half straight. Haltere length $0.7-0.8 \mathrm{~mm}$, brownish yellow to pale brown. 


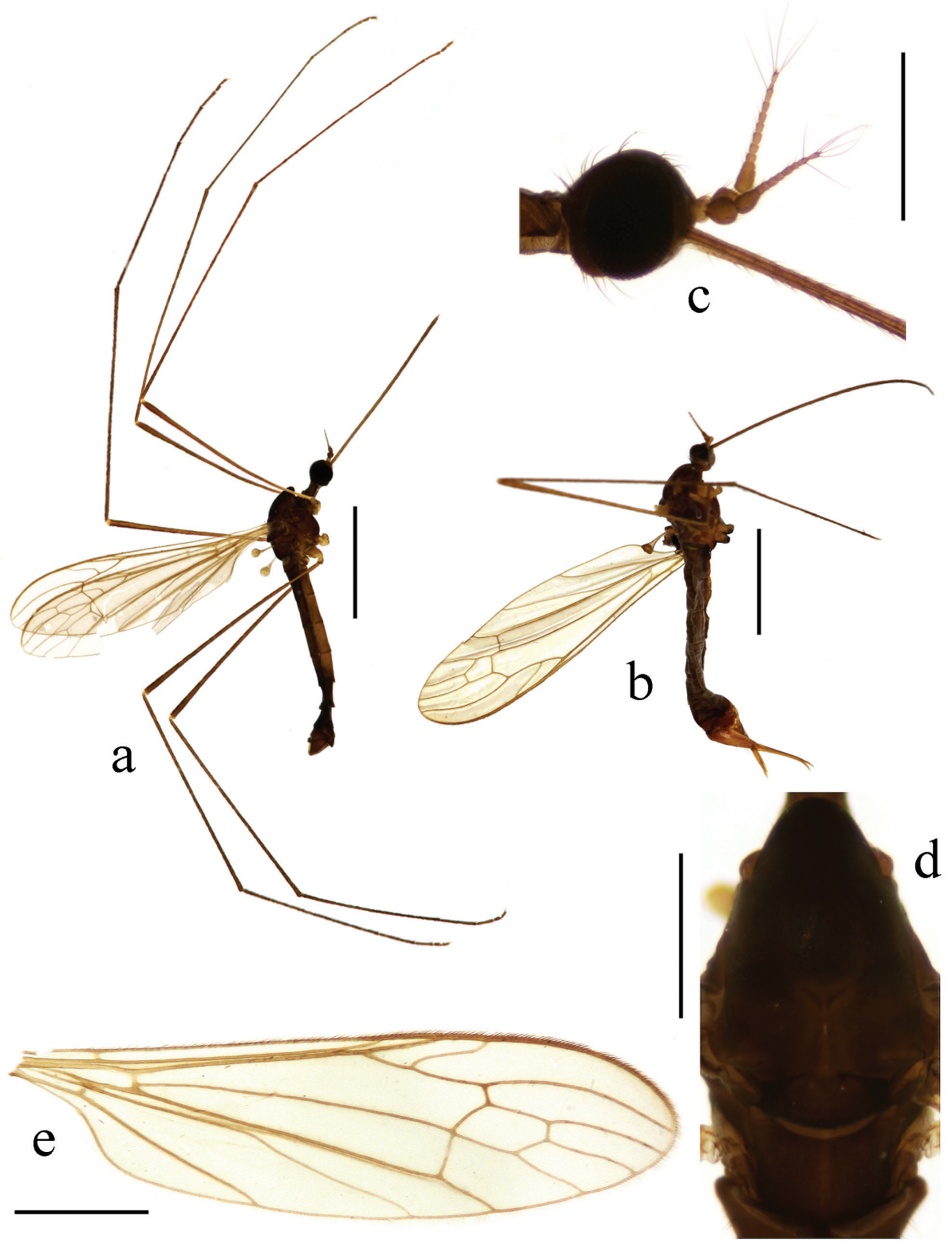

Figure I I. Toxorhina (Ceratocheilus) tinctipennis (Alexander, 1930). a Male habitus, lateral view b Female habitus (holotype), lateral view c Head, dorsal view d Thorax, dorsal view e Wing. Scale bar: $\mathbf{a}=2.0 \mathrm{~mm} ; b=2.0 \mathrm{~mm} ; \mathbf{c}=0.5 \mathrm{~mm} ; \mathbf{d}=0.5 \mathrm{~mm} ; \mathbf{e}=1.0 \mathrm{~mm}$.

Abdomen (Fig. 11a-b). Generally dark brown. Segments six to eight darker. Hairs on abdomen dark brown.

Hypopygium (Fig. 12). Generally dark brown. Gonocoxite conical, short and stout, dorsal face with a blunt lobe near base, this lobe with numerous setae. Gono- 

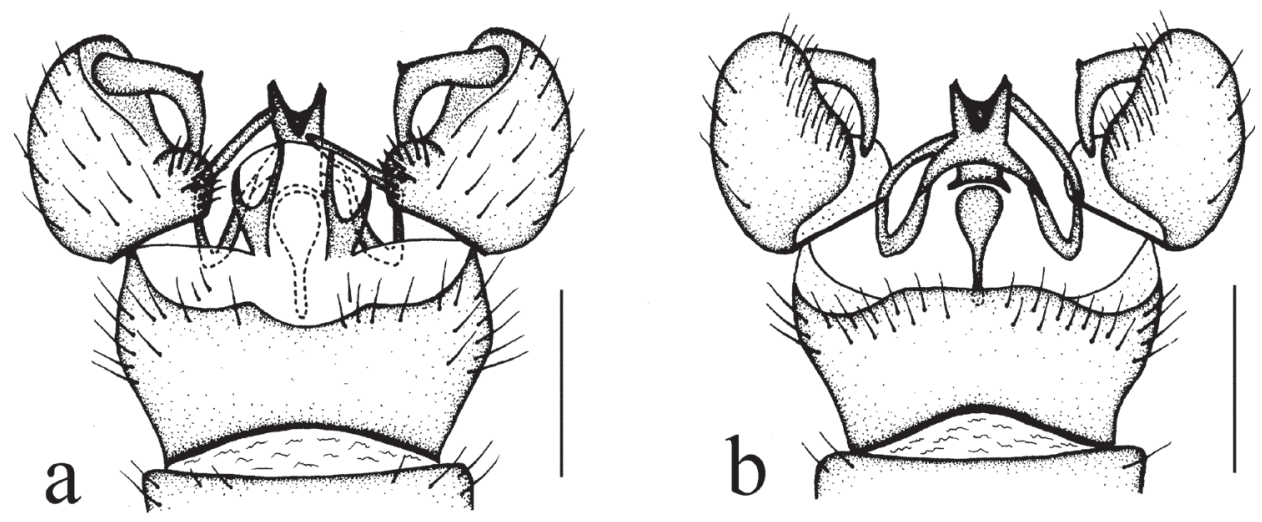

Figure 12. Toxorhina (Ceratocheilus) tinctipennis (Alexander, 1930). a Male hypopygium, dorsal view b Male hypopygium, ventral view. Scale bar: $\mathbf{a}-\mathbf{b}=0.2 \mathrm{~mm}$.

stylus with a very small spine near middle. Interbase rod-shaped. Aedeagus with tip divergent, rodS short.

Female (Fig. 11b). Body length 7.0-7.5 mm, wing length 6.0-6.5 mm, rostrum length $4.0-4.5 \mathrm{~mm}$. Similar to male. But abdomen except hypopygium uniformly dark brown. Tenth tergite brownish yellow. Cercus and hypogynial dark brownish yellow. Tip of hypogynial valve reaching just beyond middle of cercus.

Specimens examined. Holotype female (USNM), China: Taiwan, Jiayi, Mt. Ali (1981-2438 m), 1929.VII.7, Syuti Issiki. (One wing and one fore leg are mounted on a similarly labeled microscope slide. Only one mid leg is still attached to the dry mounted body, and the remaining four legs are absent.) Other materials: 8 males 1 female (CAU), China: Taiwan, Jiayi, Mt. Ali (2326' $\left.24 " \mathrm{~N}, 120^{\circ} 46^{\prime} 48^{\prime \prime} \mathrm{E}, 1100 \mathrm{~m}\right)$, 2012.VI.7, Lihua Wang.

Distribution. China (Taiwan).

Remarks. Male of this species is described and illustrated for the first time. For description and illustration of this species, also see Alexander (1930).

\section{Toxorbina (Ceratocheilus) univirgata sp. $\mathbf{n}$.}

http://zoobank.org/160ED401-82B6-4CA4-ABCF-348F53F81562

Figs $13-14$

Diagnosis. Prescutum brownish yellow with three broad brown stripes. Pleuron yellow with one dark brown stripe. Wing tinged pale grey; $\mathrm{R}_{2+3}$ ending beyond end of basal section of $\mathrm{R}_{4+5}$, basal section of $\mathrm{CuA}_{1}$ slightly before fork of $\mathrm{M}$. Sternites of abdomen brown with basal several segments paler. Gonostylus with base stout, middle with a stout and ventrally curved spine. Rods of aedeagus very long.

Description. Male. Body length $5.5 \mathrm{~mm}$, wing length $5.5 \mathrm{~mm}$, rostrum broken with remaining part length $1.5 \mathrm{~mm}$. 

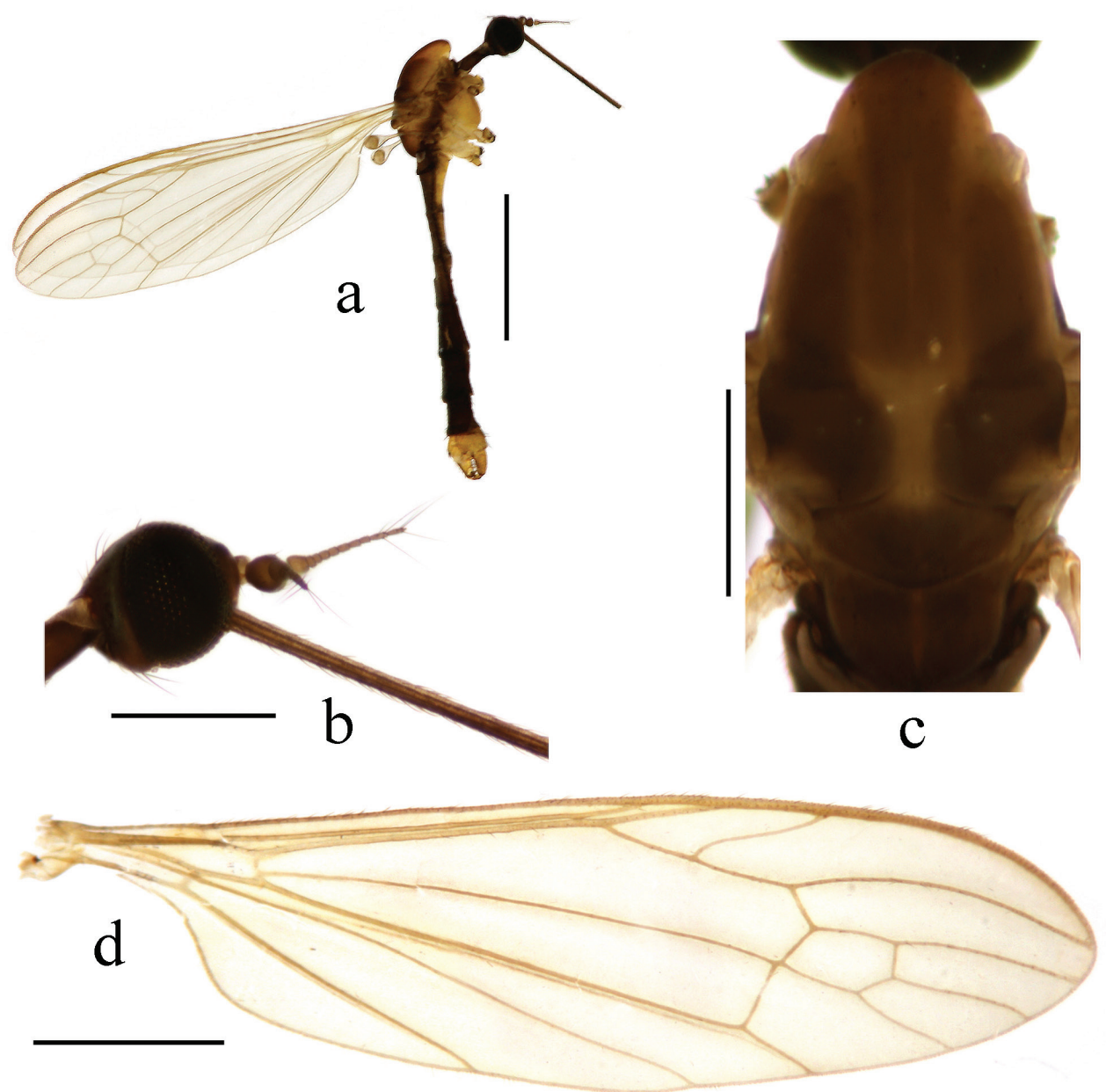

Figure 13. Toxorhina (Ceratocheilus) univirgata sp. n. a Male habitus, lateral view b Head, lateral view c Thorax, dorsal view $\mathbf{d}$ Wing. Scale bar: $\mathbf{a}=2.0 \mathrm{~mm} ; \mathbf{b}=0.5 \mathrm{~mm} ; \mathbf{c}=0.5 \mathrm{~mm} ; \mathbf{d}=1.0 \mathrm{~mm}$.

Head (Fig. 13b). Dark brown to brownish black. Hairs on head dark brown. Antenna length $0.6 \mathrm{~mm}$. Scape and pedicel dark brown; flagellomeres brown. Pedicel enlarged and nearly globose. First flagellomere subconical; remaining flagellomeres cylindrical, each flagellomere longer and slenderer than previous one, terminal two flagellomeres longest with several long hairs. Rostrum dark brown with dark brown hairs.

Thorax. Pronotum dark brown. Prescutum brownish yellow with three broad brown stripes. Scutum dark brown with middle area paler, each lobe with a light yellow spot. Scutellum and mediotergite dark brown (Fig. 13c). Pleuron (Fig. 13a) yellow with one dark brown stripe extending from cervical region to base of abdomen. Hairs on thorax dark brown. Coxae pale yellow; trochanters yellow with tips black; other parts missing. Wing (Fig. 13d) tinged pale grey; veins pale brown. Venation: $\mathrm{Sc}_{1}$ ending near middle of Rs, $\mathrm{Sc}_{2}$ before origin of Rs; $\mathrm{R}_{2+3}$ ending beyond end of basal section 

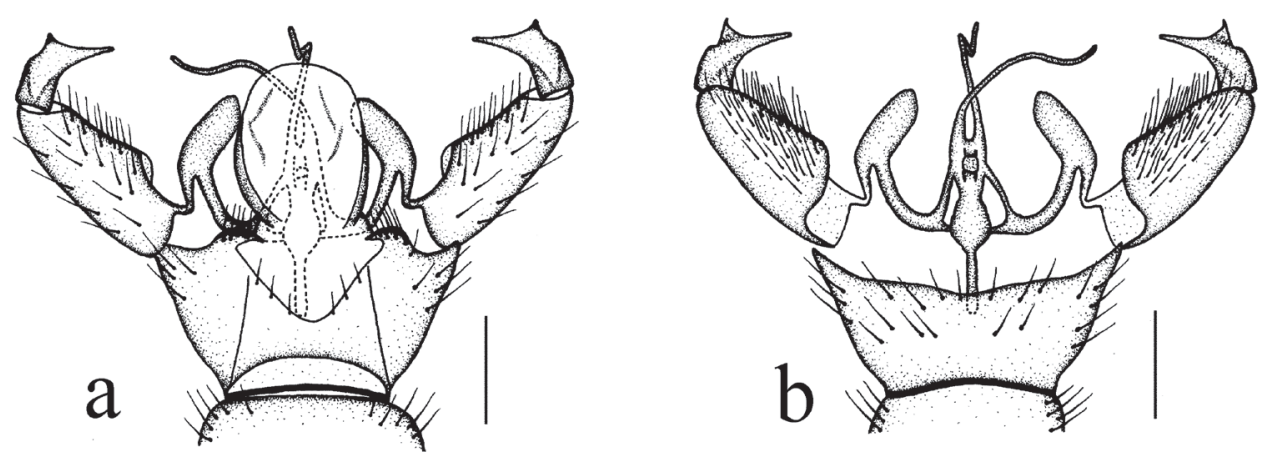

Figure 14. Toxorhina (Ceratocheilus) univirgata sp. n. a Male hypopygium, dorsal view b Male hypopygium, ventral view. Scale bar: $\mathbf{a}-\mathbf{b}=0.2 \mathrm{~mm}$.

of $\mathrm{R}_{4+5}$; basal section of $\mathrm{CuA}_{1}$ slightly before fork of $\mathrm{M}$; $\mathrm{A}_{1}$ curved relatively smoothly. Haltere length $0.8 \mathrm{~mm}$, pale yellow with knob darker.

Abdomen (Fig. 13a). Tergites brownish black. Sternites brown with basal several segments paler. Segment five to eight black with segment eight paler. Segment nine yellow. Hairs on abdomen brownish black.

Hypopygium (Fig. 14). Generally yellow to pale brownish yellow. Gonocoxite conical. Gonostylus with base stout, middle with a stout and ventrally curved spine. Interbase nearly oval, tip blunt. Aedeagus with tip divergent, rods filiform and very long.

Female. Unknown.

Type material. Holotype male (CAU), China: Yunnan, Lvchun, Mt. Huanglian (263' $\left.36^{\circ} \mathrm{N}, 113^{\circ} 28^{\prime} 12^{\prime \prime E}, 1542 \mathrm{~m}\right), 2013$.VII.25, Mengchao Tan (light trap).

Distribution. China (Yunnan).

Etymology. The specific epithet is an adjective and refers to the dark brown stripe on pleuron (from Latin univirgatus = uni- (adj., meaning "single") + virgatus (adj., meaning striped)).

Remarks. This new species is somewhat similar to $T$. (C.) fulvicolor in having the similar male hypopygium and wing, but it can be easily distinguished from the latter by the prescutum (Fig. 13c) brownish yellow with three broad brown stripes, pleuron (Fig. 13a) yellow with one dark brown stripe, and abdomen with tergites brownish black (Fig. 13a). In T. (C.) fulvicolor, the prescutum is pale brownish yellow and irregularly variegated, the pleuron is pale yellow, and the tergites of the abdomen are brownish yellow with the posterior borders narrowly brown (Alexander 1967).

\section{Acknowledgements}

We are very grateful to Dr. Jon K. Gelhaus (Philadelphia) and Dr. David G. Furth (Washington D.C.) for their great help during the study of type material from USNM, and two anonymous reviewers for providing useful comments on the drafts of this paper. 


\section{References}

Alexander CP (1923) Undescribed crane flies from Formosa and Luzon (Tipulidae, Diptera). Philippine Journal of Science 22: 467-481.

Alexander CP (1928) New or little-known Tipulidae from eastern Asia (Diptera). II. Philippine Journal of Science 35: 455-489.

Alexander CP (1929) New or little-known Tipulidae from the Philippines (Diptera). V. Philippine Journal of Science 40: 239-273.

Alexander CP (1930) New or little-known Tipulidae from eastern Asia (Diptera). VI. Philippine Journal of Science 42: 59-83.

Alexander CP (1934) New or little-known Tipulidae from eastern Asia (Diptera). XVIII. Philippine Journal of Science 53: 267-300.

Alexander CP (1936) New or little-known Tipulidae from eastern Asia (Diptera). XXXIII. Philippine Journal of Science 61: 169-203.

Alexander CP (1947) Notes on the tropical American species of Tipulidae (Diptera). III. The specialized Eriopterini: Rhabdomastix, Cryptolabis, Erioptera, Molophilus, Styringomyia, Toxorhina, and allies. Revista de Entomologia 18: 317-360.

Alexander CP (1956) New or little-known Tipulidae (Diptera). C. Oriental-Australasian species. Annals and Magazine of Natural History (12) 9:36-53. doi: 10.1080/00222935608655719

Alexander CP (1962) New exotic crane-flies (Tipulidae: Diptera). Part V. Entomological News 73: $122-129$.

Alexander CP (1966) Undescribed species of crane flies from the Himalaya mountains (Diptera: Tipulidae). XIII. Journal of the New York Entomological Society 74: 180-184.

Alexander CP (1967) Undescribed species of crane flies from the Himalaya mountains (Diptera: Tipulidae). XV. Journal of the New York Entomological Society 75: 183-187.

Alexander CP (1970) New and little-known Indian craneflies (Diptera: Tipulidae). III. Oriental Insects 4: 77-88. doi: 10.1080/00305316.1970.10433943

Alexander CP, Byers GW (1981) Tipulidae. In: McAlpine JF, Peterson BV, Shewell GE, Teskey HJ, Vockeroth JR, Wood DM (Eds) Manual of Nearctic Diptera. Vol. I. Biosystematic Research Centre, Ottawa, Ontario, 153-190.

Brunetti E (1918) Revision of the Oriental Tipulidae with descriptions of new species, Part 2. Records of the Indian Museum 15: 255-344.

Edwards FW (1926) Diptera Nematocera from the mountains of Borneo. Sarawak Museum Journal 3: 243-278.

Edwards FW (1933) Diptera Nematocera from Mount Kinabalu. Journal of the Federated Malay States Museums 17: 223-296.

Joseph ANT (1979) The Brunetti types of Tipulidae (Diptera) in the collection of the Zoological Survey of India: Part XIII. The genera Molophilus, Styringomyia and Toxorhina. Oriental Insects 13: 29-39. doi: 10.1080/00305316.1979.10433539

Loew H (1850) Uber den Bernstein und die Bernsteinfauna. Programm K. Realschule zu Meseritz, 1850: 3-44.

McAlpine JF (1981) Morphology and terminology, Adults. In: McAlpine JF, Peterson BV, Shewell GE, Teskey HJ, Vockeroth JR, Wood DM (Eds) Manual of Nearctic Diptera. Vol. I. Biosystematic Research Centre, Ottawa, Ontario, 9-63. 
Oosterbroek P (2014) Catalogue of the Craneflies of the World, (Diptera, Tipuloidea, Pediciidae, Limoniidae, Cylindrotomidae, Tipulidae). http://nlbif.eti.uva.nl/ccw/ [accessed 20 February 2014]

Osten Sacken CR (1869) Monographs of the Diptera of North America. Part IV. Smithsonian Miscellaneous Collections 8(219): 1-345.

Podenas S, Gelhaus J (2007) Identification keys for Limoniinae (Diptera, Limoniidae) of Mongolia and adjacent territories. Vilnius, Lithuania, $85 \mathrm{pp}$.

Ribeiro GC (2006) Homology of the gonostylus in crane flies, with emphasis on the families Tipulidae and Limoniidae (Diptera, Tipulomorpha). Zootaxa 1110: 47-57.

Wesche W (1910) On the new tipulid subfamily Ceratocheilinae. Journal of the Linnean Society of London, Zoology 30: 355-360. doi: 10.1111/j.1096-3642.1910.tb02141.x 